\title{
Two-dimensional Covalent Organic Framework Thin Films Grown in Flow
}

\author{
Ryan P. Bisbey, Catherine R. DeBlase, Brian J. Smith, William R. Dichtel* \\ Department of Chemistry and Chemical Biology, Cornell University, \\ Baker Laboratory, Ithaca, New York, 14853-1301
}

\section{Supplementary Information}

\begin{tabular}{|c|}
\hline Correspondence Address \\
\hline Professor William R. Dichtel \\
Department of Chemistry and Chemical Biology \\
Cornell University \\
Baker Laboratory \\
Ithaca, NY 14853-1301 (USA) \\
Tel: (+1)-607-254-2356 \\
Fax: (+1)-607-255-4137 \\
Email: wdichtel@cornell.edu \\
\hline
\end{tabular}

\section{Table of Contents}
A. Materials and Instrumentation
B. Experimental Protocols
C. Quartz-Crystal Microbalance Measurements
D. Grazing Incident X-Ray Diffraction
E. Profilometry
F. FT-IR Spectroscopy
G. Atomic Force Microscopy
H. Scanning Electron Microscopy
I. References 
A. Materials and Instrumentation. 2,7-pyrenebis(boronic acid) ${ }^{1}$ and 4,4'-diphenylbutadiynebis(boronic acid $)^{2}$ were prepared according to literature procedures. All reagents were purchased from commercial sources and used without further purification. $\mathrm{MeOH}$ was purchased from commercial sources and purified using a custom-built alumina-column based solvent purification system. Other solvents were purchased from commercial sources and dried over activated $3 \AA$ molecular sieves.

Quartz Crystal Microbalance (QCM) measurements were performed on a Stanford Research Systems QCM200 with flow cell accessory (O100FM) with Pt/Ti/quartz resonator substrates whose resonate frequency was approximately 4.9 MHz (O100RX4). Capacitance cancellations were done once the setup had been allowed to equilibrate to temperature, flow, and solvent $(\sim 2$ h). For flow experiments a KD Scientific syringe pump (KDS200) was used with NormJect syringes.

UV/Vis/NIR absorbance and turbidity spectra were recorded on a Cary 5000 UV/Vis/NIR spectrophotometer with a mercury lamp. Cuvette temperature and stirring were regulated with a Quantum Northwest Temperature Controller.

Sonication was performed with a Branson 3510 ultrasonic cleaner with a power output of $100 \mathrm{~W}$ and a frequency of $42 \mathrm{kHz}$.

Atomic force micrographs (AFM) were taken on an Asylum MFP-3D-BIO operating in tapping mode and equipped with a Tap150Al-G Si tip with aluminum reflex coating using a set point of $550 \mathrm{mV}$ and an integral gain of 13.

Profilomtery data was obtained on a Tencor Alpha Step 500. Using a $5000 \mu \mathrm{m}$ scan length and $200 \mathrm{~Hz}$ scan rate with $8.0 \mathrm{mg}$ of stylus force. Thickness was measured at the edge of the organic film created by the O-ring of the QCM crystal holder.

Grazing incidence X-ray diffraction (GI-XRD) was performed at the G2 station at Cornell High Energy Synchrotron Source (CHESS) using a beam energy of $10.06 \pm 0.01 \mathrm{keV}(\lambda=0.1232 \mathrm{~nm})$, selected using a single-crystal Be crystal monochromator. Motorized slits were used to define a $0.2 \times 3(\mathrm{~V} \times \mathrm{H}) \mathrm{mm}^{2}$ beam, with a typical flux of $2 \times 10^{10}$ photons $\mathrm{s}^{-1}$. The data were collected using a 640-element 1D diode-array, of which each element incorporates its own pulse counting electronics capable of count rates of $\sim 105$ photons $\mathrm{s}^{-1}$. A set of $0.1^{\circ}$ Soller slits were used on the 
detector arm to define the in-plane resolution. The scattering geometry is described in detail elsewhere. ${ }^{3}$ Each data set was collected by scanning the detector with the sample stationary. The incidence angle, $\alpha$, between the beam and sample surface was $0.175^{\circ}$. Axes labels $\mathrm{Q} \perp$ and $\mathrm{Q}_{\|}$are defined using the GISAXS convention $\mathrm{Q}_{\perp}=4 \pi / \lambda \sin (\delta / 2)$ and $\mathrm{Q}_{\|}=4 \pi / \lambda \sin (v / 2)$, where $\delta$ and $v$ are the vertical and horizontal scattering angles, respectively. At $\alpha=\delta=0$, $\mathrm{Q}_{\|}$and $\hbar \mathrm{Q} \perp$ (where $\hbar$ is Planck's constant) are the components of momentum transfer parallel and perpendicular to the sample surface, respectively.

Fourier transform infrared (FT-IR) spectra were taken using Nicolet iS10 FTIR, with ZnSe ATR attachment for bulk powders. FT-IR of films were taken using Bruker Hyperion FT-IR Microscope in reflectance mode under a $\mathrm{N}_{2}$ purge. A grazing incidence objective and p-polarized incident light was used to maximize the signal from the films. A gold mirror was used as reference and spectra were background corrected to account differences between the reference and film substrates

Scanning Electron Microscopy (SEM) images were obtained using a LEO 1550 FESEM at a 3 $\mathrm{kV}$ accelerating voltage and using the in-lens secondary electron detector with an $\sim 5 \mathrm{~mm}$ working distance. 


\section{B. Experimental Protocols}

General Procedures for COF Reaction Mixture Preparation. 1,4-phenylenebis(boronic acid) 1, 4,4'-diphenyl-butadiynebis(boronic acid) 2, 2,7-pyrenebis(boronic acid) $\mathbf{3}$, or 4,4'-biphenylbis(boronic acid) 4 was added to dioxane / mesitylene solution $(4: 1 \mathrm{v} / \mathrm{v})$ such that the species was $12 \mathrm{mM}$. MeOH was added to such that its concentration would be $120 \mathrm{mM}$. The mixture was then gently heated until solids had dissolved and allowed to cool to RT. 2,3,6,7,10,11-hexahydroxytriphenylene (HHTP) was added to the solution such that its concentration was $8 \mathrm{mM}$ and then sonicated until the solution appeared homogenous. The solution was then filtered $(0.45 \mu \mathrm{m}$ PTFE) to remove any trace residual particulate and was used to grow COF films using the flow cell setup.

Turbidity characterization. A septum-sealed, screw-capped cuvette of homogenous monomer solution $(1.5 \mathrm{~mL})$ was heated to the appropriate temperature and the suspension turbidity was monitored at $1310 \mathrm{~nm}$ (1 cm path length). The solution was rapidly and constantly stirred throughout the measurement to prevent precipitate settling and maintain uniform distribution.

Thin Film Growth in Flow Cell Setup. A Pt QCM substrate, was secured within the Teflon flow cell and placed in an aluminum box, Teflon tubing was fitted to the outlet and drained into a waste container, and additional Teflon tubing was coiled within the aluminum box and fitted to the inlet on the flow cell and to a barbed-luer lock adapter outside the box. A syringe was fitted to the luer-lock adapter and was loaded onto a syringe pump. The length of this tubing and flow rate (typically $0.1-2 \mathrm{~mL}$ per $\mathrm{min}$ ) correspond to a residence time that was measured at RT before each experiment using a syringe containing dioxane / mesitylene $(4: 1 \mathrm{v} / \mathrm{v})$. The aluminum box was filled with sand to cover the coiled tubing and flow cell and heated to a desired temperature via hot plate, typically $90^{\circ} \mathrm{C}$. Once at temperature, the flow cell setup was allowed to equilibrate under flow of dioxane / mesitylene $(4: 1 v / v)$. Sometimes sinusoidal noise is present in the QCM response. This was correlated with approximate $\pm 1{ }^{\circ} \mathrm{C}$ oscillations of the hot plate and sand bath temperature about the set point temperature. Once equilibrated, the monomer solution was introduced by exchanging syringes. Bubbles were pulled from the tubing into the syringe before running the syringe pump to flow the new solution. After the desired volume of monomer solution was passed through the flow cell, the syringe was exchanged quickly with dioxane / mesitylene $(4: 1 v / v)$ (or for etching experiments the etching solutions) and flushed through the 
flow cell to clear the tubing and flow cell of residual monomer solution at the maximum rate of $85 \mathrm{~mL} \mathrm{~min}{ }^{-1}$. Finally the flow rate of the pure solvent mixture was returned to the original flow rate. Films obtained from this setup are $3.25 \mathrm{~cm}^{2}$ in area.

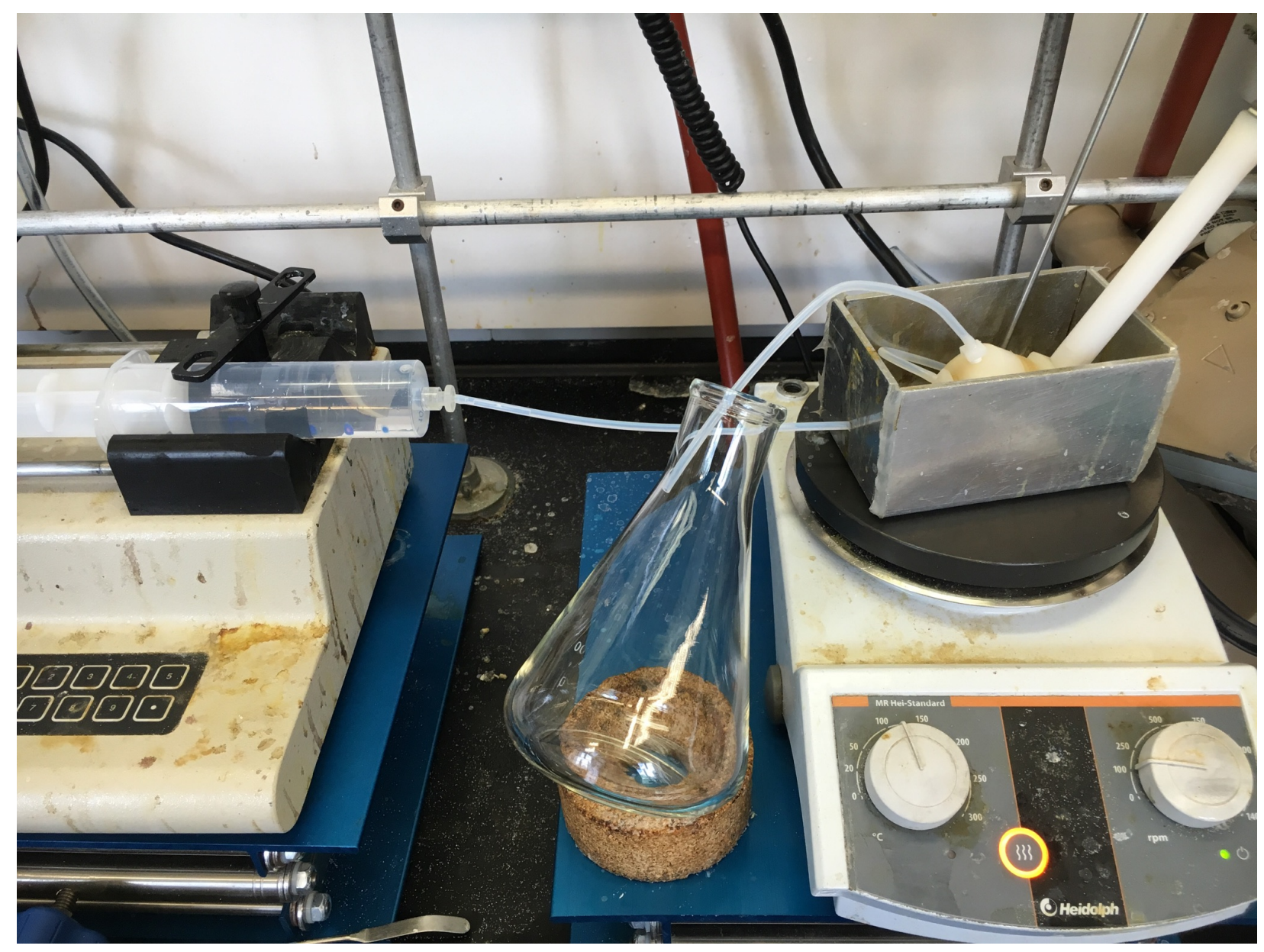

Figure S1. Photograph of flow cell experimental setup for COF film growth (without sand).

\section{Static Thin Film Growth}

For static growth the QCM was submerged open face (i.e. without the flow cell accessory) in dioxane / mesitylene $(150 \mathrm{~mL}, 4: 1 \mathrm{v} / \mathrm{v})$ inside of a sealed lypholyzation chamber equipped with with stir bar. The setup was equilibrated at temperature under solvent with no flow in a $90{ }^{\circ} \mathrm{C}$ silicon oil bath at $100 \mathrm{rpm}$ stirring. Once equilibrated, the blank solvent was decanted and 150 $\mathrm{mL}$ a COF monomer solution was added at room temperature. The chamber was quickly resealed and returned to the $90{ }^{\circ} \mathrm{C}$ bath. After a given reaction time, the resulting COF films were removed and washed with additional dioxane / mesitylene $(4: 1 \mathrm{v} / \mathrm{v})$. When noted, the films were cleaned of excess by sonicatation in dioxane / mesitylene $(4: 1 v / v) 3 \times 10 \mathrm{~s}$. 


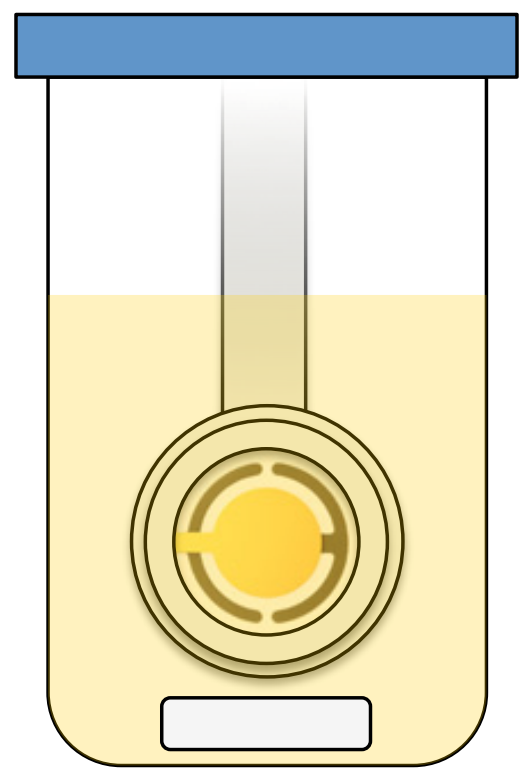

Figure S2. Diagram of experimental setup for COF static film growth. 


\section{Quartz-Crystal Microbalance (QCM) Measurements}

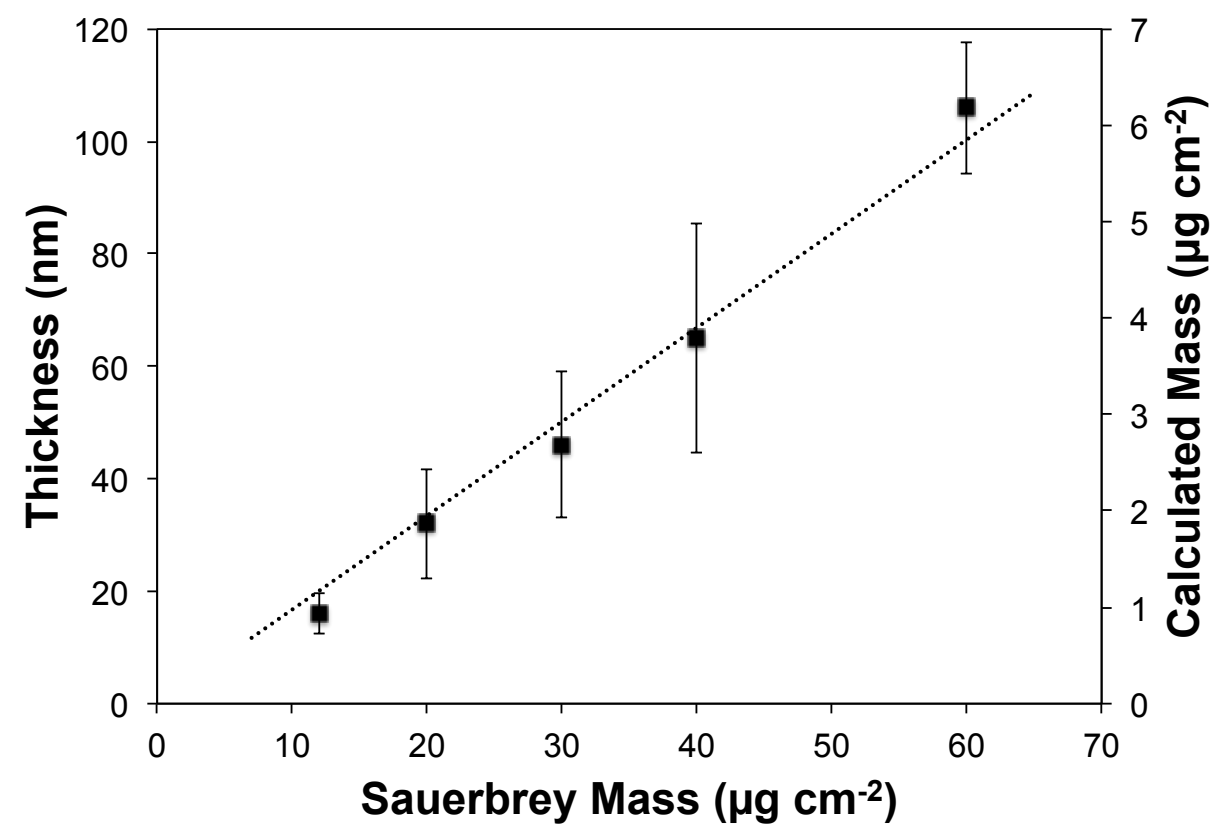

Figure S3. Film thickness measured by AFM for a given Sauerbrey mass for films grown in flow (flow rate $=0.5 \mathrm{~mL} \mathrm{~min}^{-1}, t_{r}=2.1 \mathrm{~min}$ ). The error bars indicate film RMS roughness. The calculated mass is calculated for a crystalline COF-5 film of a given thickness. This correlation is valid for COF-5 grown in flow using the specified residence time and might not remain valid for other growth conditions or 2D COF films. 

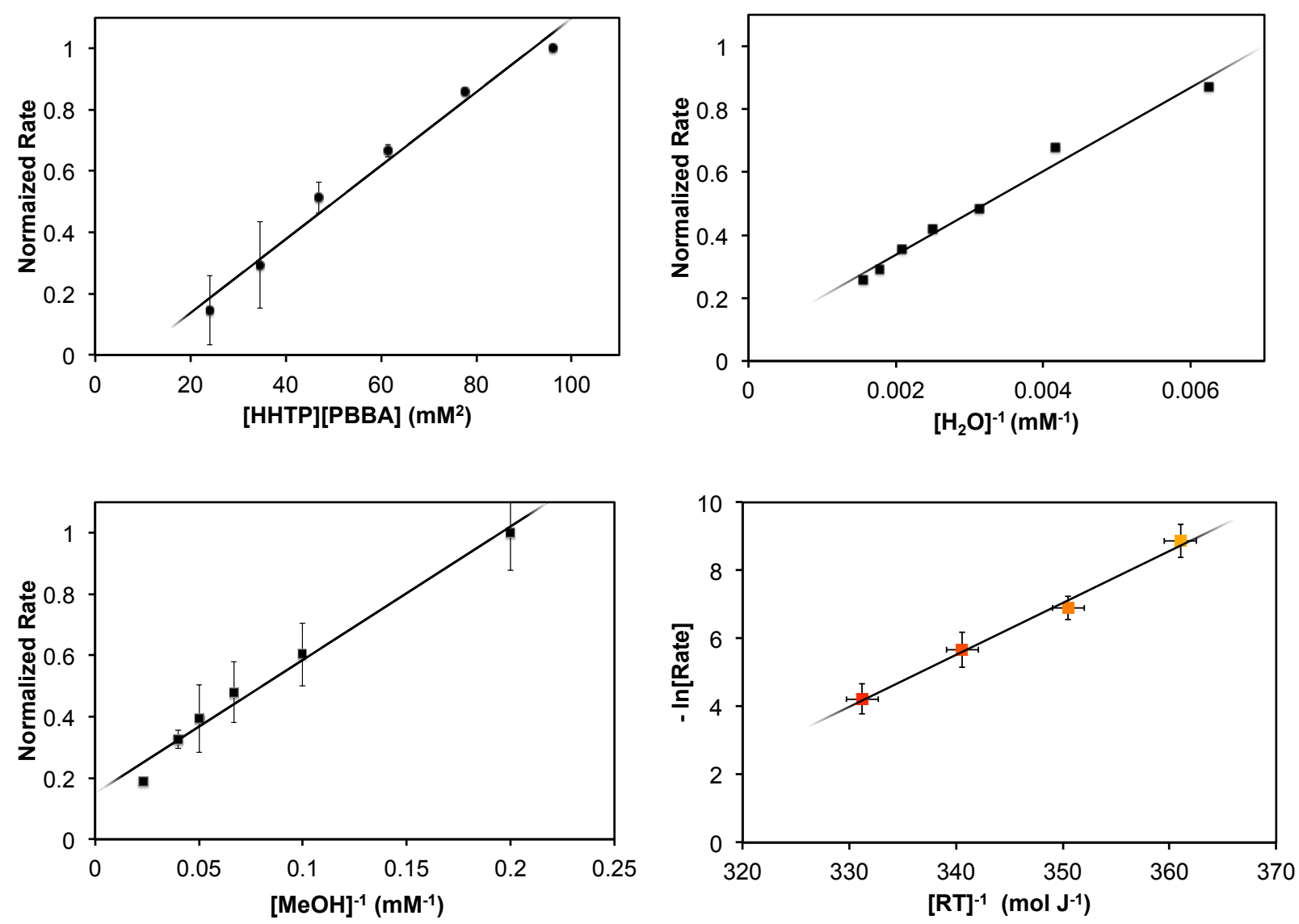

Figure S4. The rate of COF-5 film formation as determined by QCM, measured as a function of monomer concentration (top left, note: $\mathrm{MeOH}$ varied to remain at 15 equivalents relative to [HHTP]), added $\mathrm{H}_{2} \mathrm{O}$ (top right), added $\mathrm{MeOH}$ (bottom left), and temperature (bottom right). Error bars are provided for monomer concentration, $\mathrm{MeOH}$ concentration, and temperature and are the standard deviation of the rate measured over 3 trials. The horizontal error bars for temperature indicate the range of temperatures measured by the hot-plate thermocouple as it oscillated about the set-point temperature $\left( \pm 0.5^{\circ} \mathrm{C}\right)$. These experiments provide a means to tune the growth rate by manipulating these parameters. 


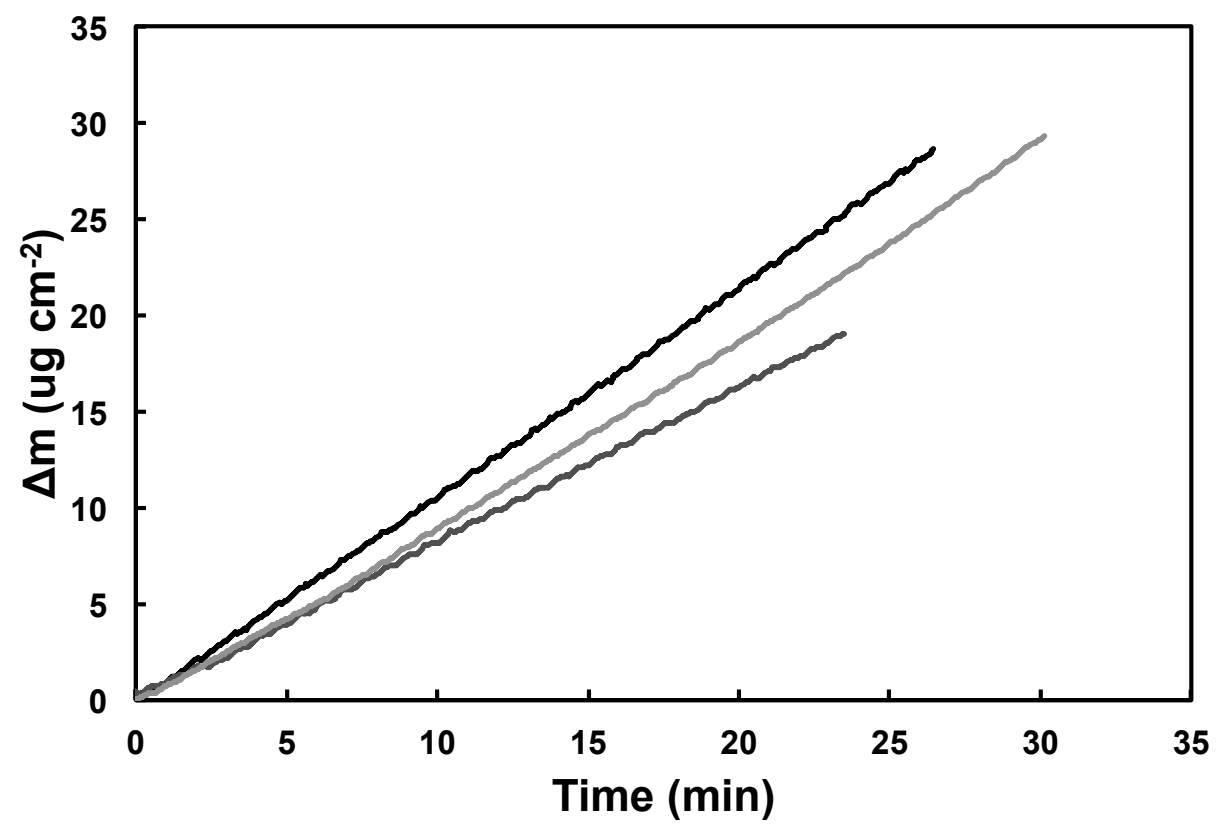

Figure S5. The variation in film growth over multiple samples as measured by QCM under identical conditions (stock solution, flow rate $=0.5 \mathrm{~mL} \mathrm{~min}^{-1}, t_{r}=50 \%$ of induction period). The average rate is $0.96 \pm 0.13 \mu \mathrm{g} \mathrm{cm}^{-2} \mathrm{~min}^{-1}$.

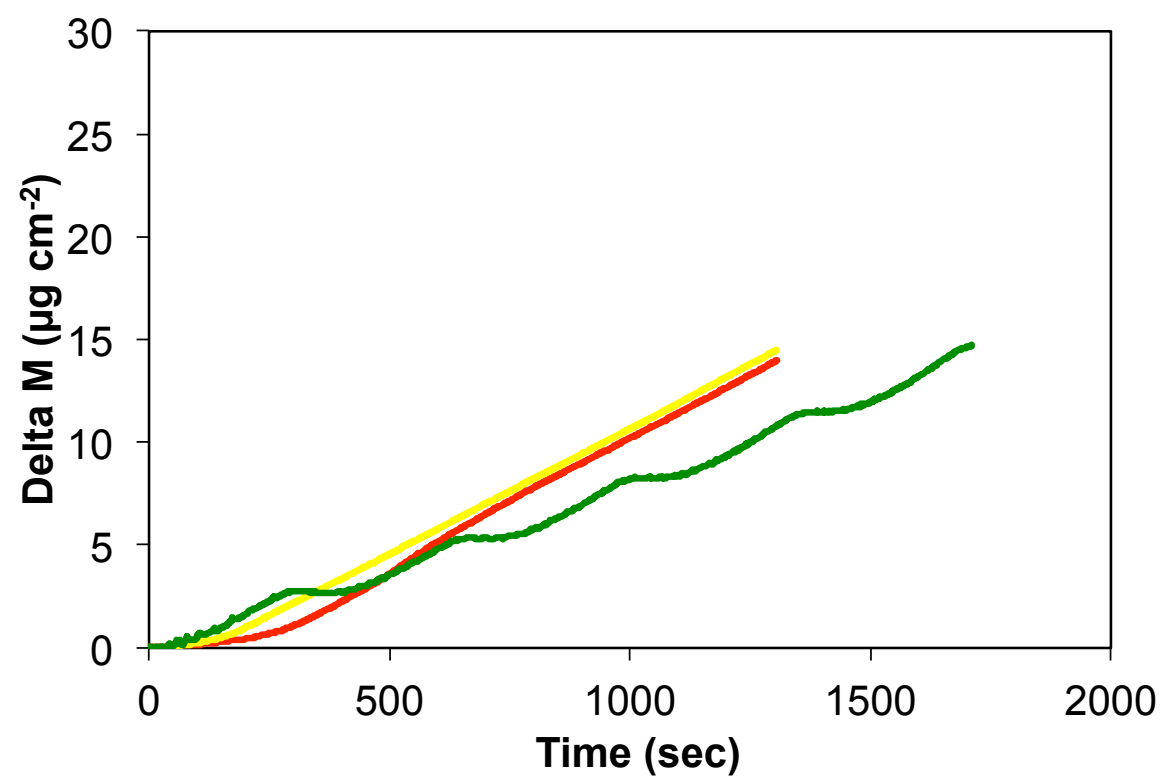

Figure S6. COF-5 film formation at flow rates of $0.25,0.5$, and $1.0 \mathrm{~mL} \mathrm{~min}^{-1}$ (red, yellow, and green traces, respectively) at equivalent residence times (60 s). 


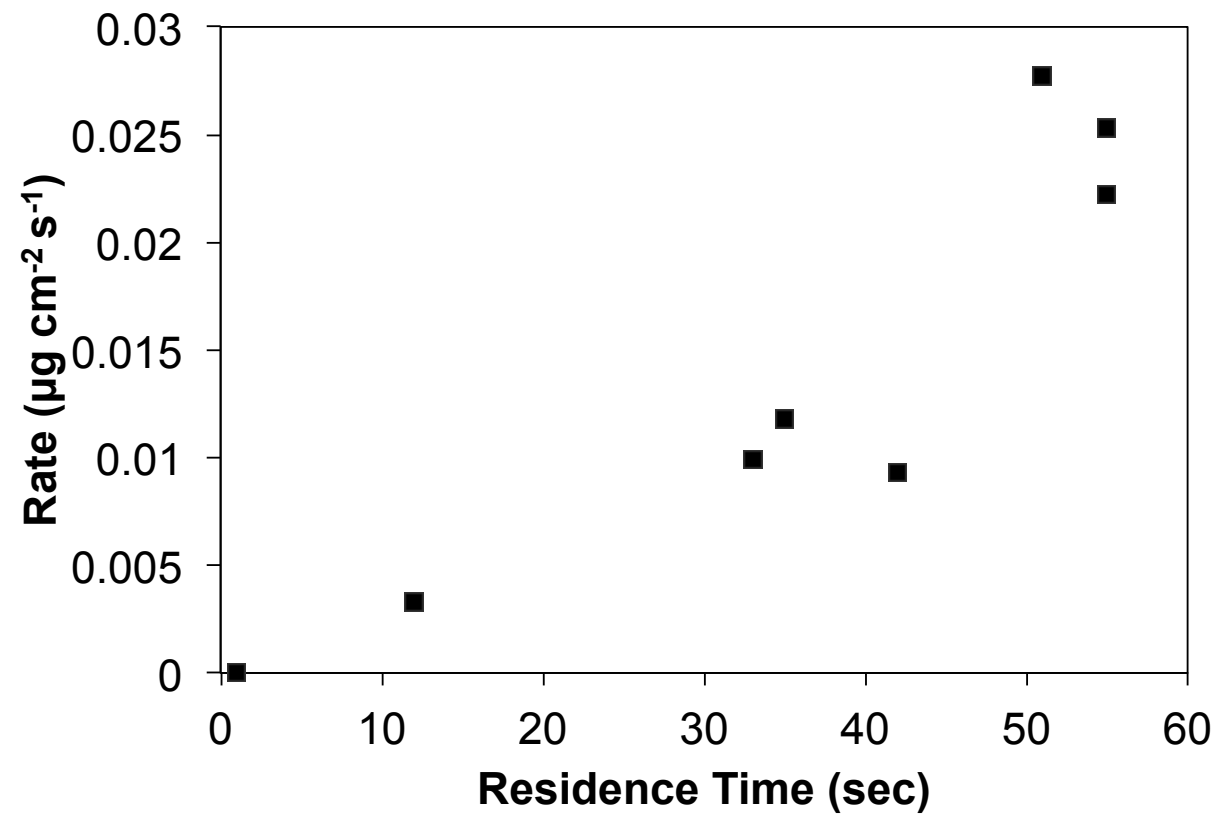

Figure S7. The rate of COF-5 film formation as a function of $t_{r}$ (flow rate $\left.=1.0 \mathrm{~mL} \mathrm{~min}{ }^{-1}\right)$. 


\section{Grazing Incident X-ray Diffraction (GI-XRD)}
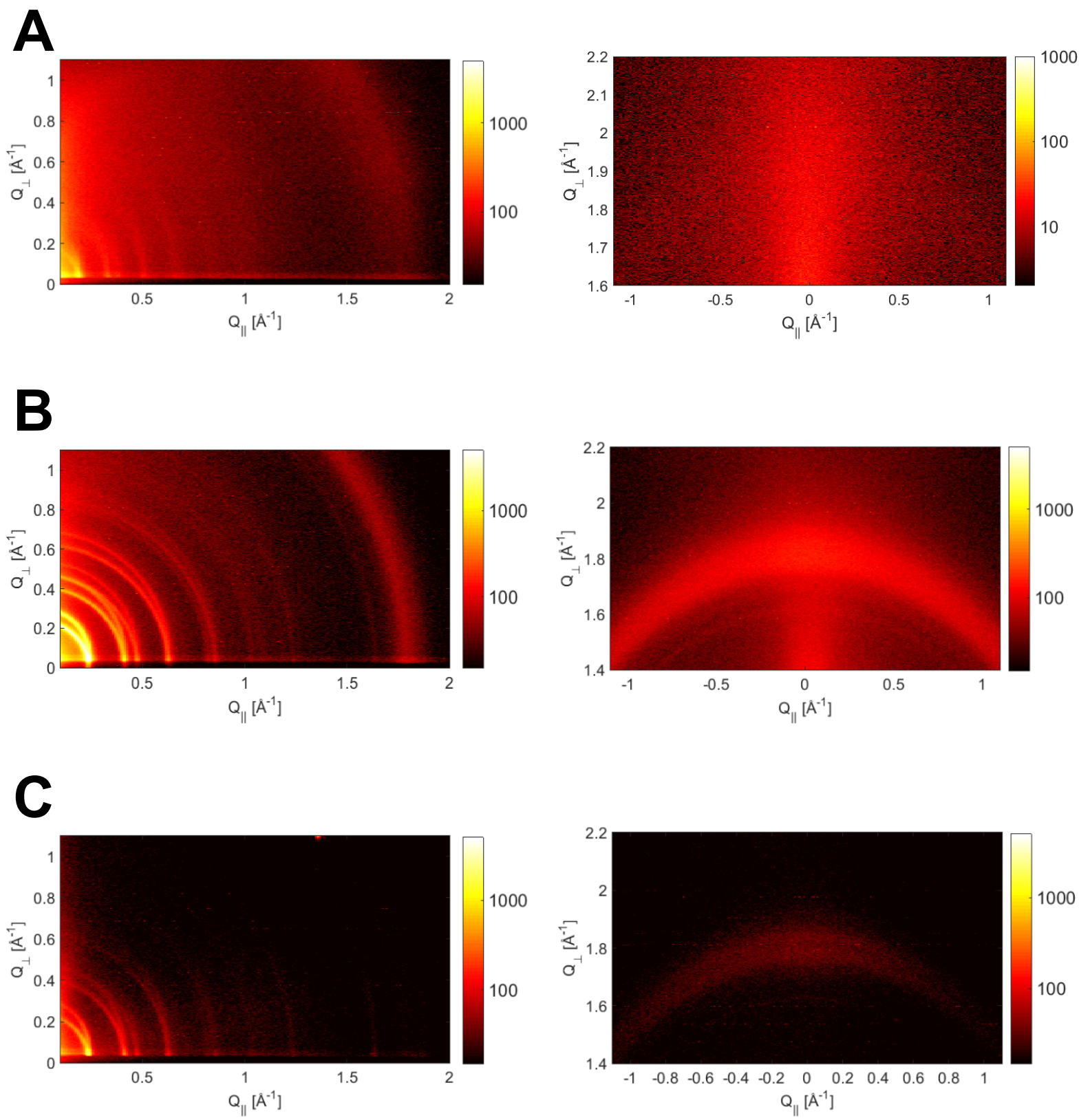

Figure S8. (A) GI-XRD patterns of COF-5 (HHTP + 1) film grown in flow at a $t_{r} 90 \%$ of the onset of powder precipitation as measured by turbidity experiments. (B) GI-XRD of film grown under static conditions (B) before and (C) after sonication to remove some powder contaminants. 

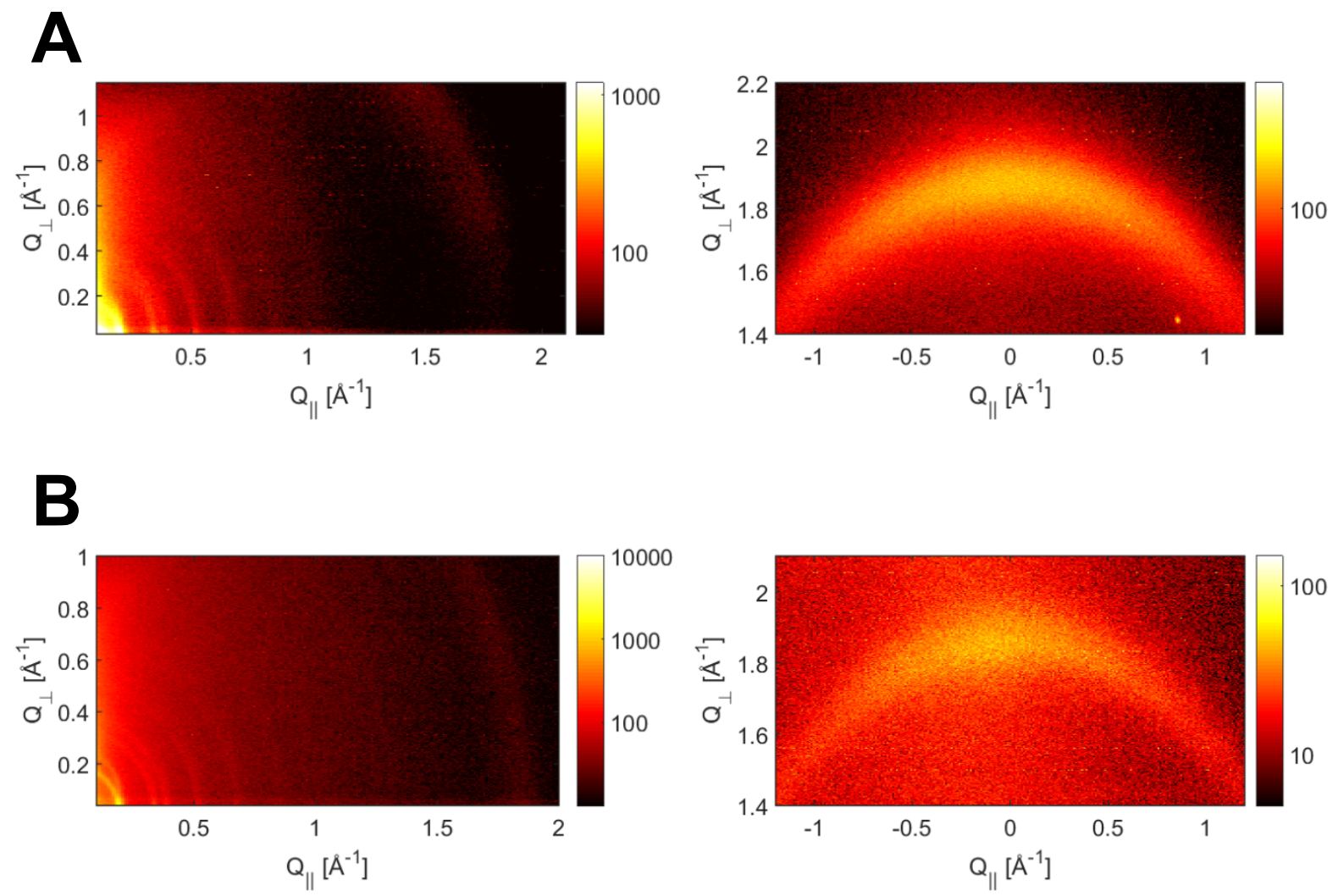

Figure S9. (A) GI-XRD patterns of TP-COF $\left(\right.$ HHTP +3 ) film grown in flow grown using a $t_{r}$ $90 \%$ of the onset of powder precipitation as measured by turbidity experiments. (B) GI-XRD patterns of film grown statically after sonication to remove some powder contaminants. 


\section{E. Profilometry}

Table S1. Film thickness as measured by profilometry showing that thicker films can be obtained by flow than after static film growth has ceased.

\begin{tabular}{|l|l|l|}
\hline COF (and Monomers) & $\begin{array}{l}\text { Flow Film Thickness (and } \\
\text { Sauerbrey Mass) }\end{array}$ & $\begin{array}{l}\text { Static Film Thickness (and } \\
\text { Final Sauerbrey Mass) }\end{array}$ \\
\hline COF-5 (HHTP + 1) & $257 \mathrm{~nm}\left(80 \mu \mathrm{g} \mathrm{cm}^{-2}\right)$ & $101 \mathrm{~nm}\left(40 \mu \mathrm{g} \mathrm{cm}^{-2}\right)$ \\
\hline DPB-COF (HHTP + 2) & $374 \mathrm{~nm}\left(80 \mu \mathrm{g} \mathrm{cm}^{-2}\right)$ & $261 \mathrm{~nm}\left(60 \mu \mathrm{g} \mathrm{cm}^{-2}\right)$ \\
\hline TP-COF (HHTP + 3) & $393 \mathrm{~nm}\left(105 \mu \mathrm{g} \mathrm{cm}^{-2}\right)$ & $354 \mathrm{~nm}\left(40 \mu \mathrm{g} \mathrm{cm}^{-2}\right)$ \\
\hline COF-10 (HHTP + 4) & $354 \mathrm{~nm}\left(75 \mu \mathrm{g} \mathrm{cm}^{-2}\right)$ & $198 \mathrm{~nm}\left(65 \mu \mathrm{g} \mathrm{cm}^{-2}\right)$ \\
\hline
\end{tabular}




\section{F. FT-IR Spectra}

A

B
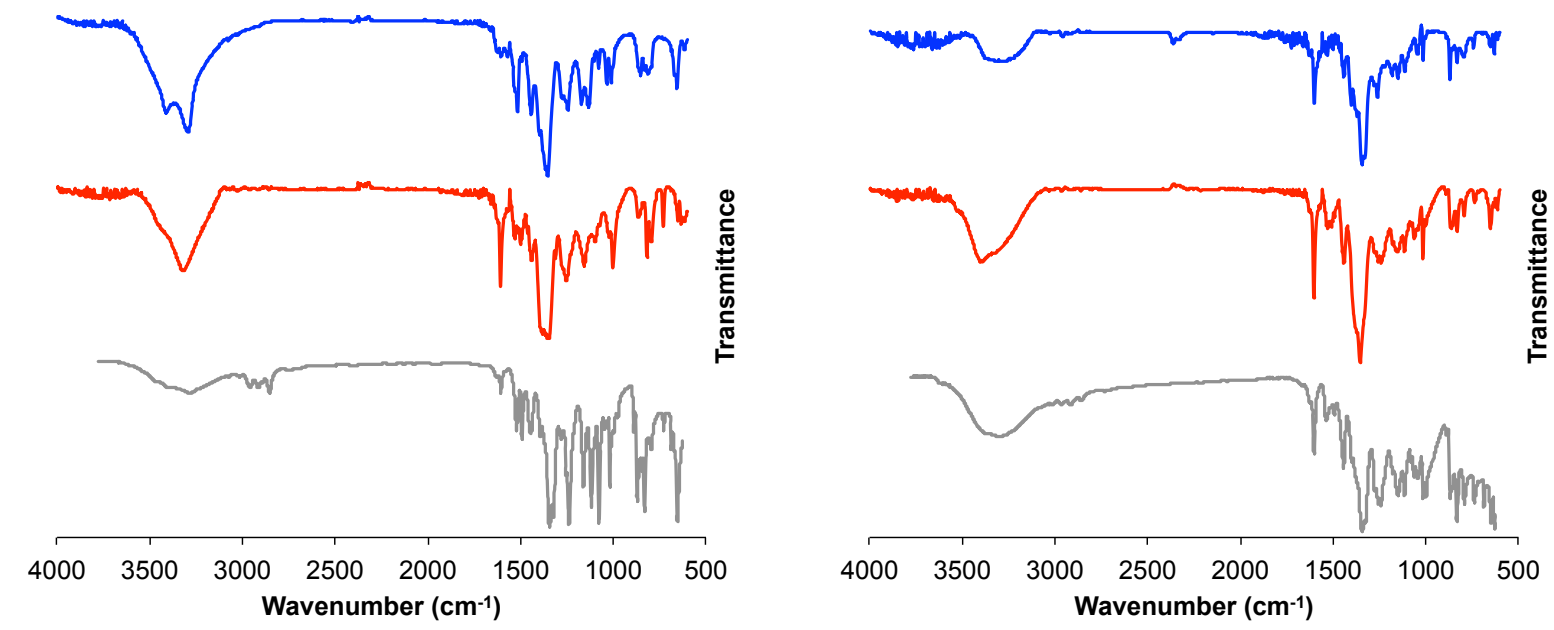

C

D
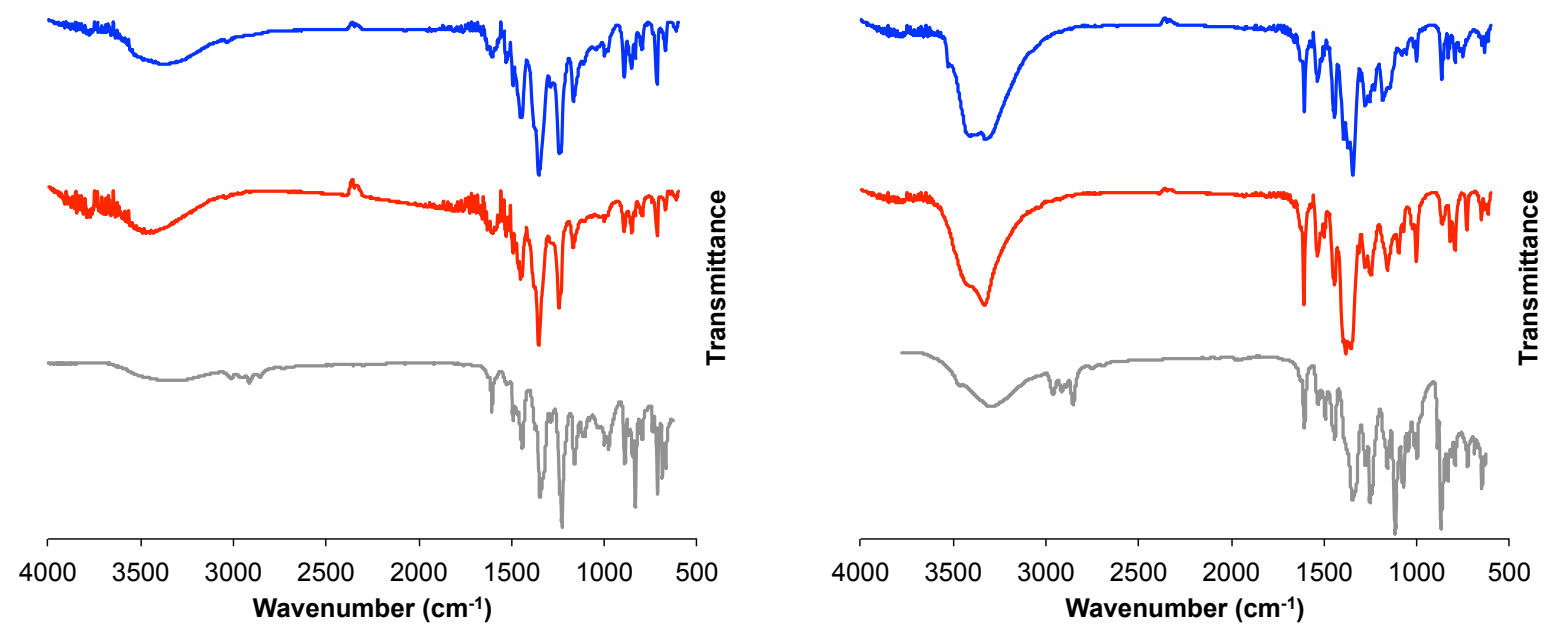

Figure S10. Grazing incidence FT-IR spectra of COF films grown from flow (blue traces), static conditions (red traces), and the FT-IR spectra of the relevant microcrystalline powder (gray traces) for COF-5, DPB-COF, TP-COF and COF-10 (A-D, respectively) formed from the condensation of HHTP and 1, 2, 3, or 4, respectively. 


\section{F. Atomic Force Microscopy}
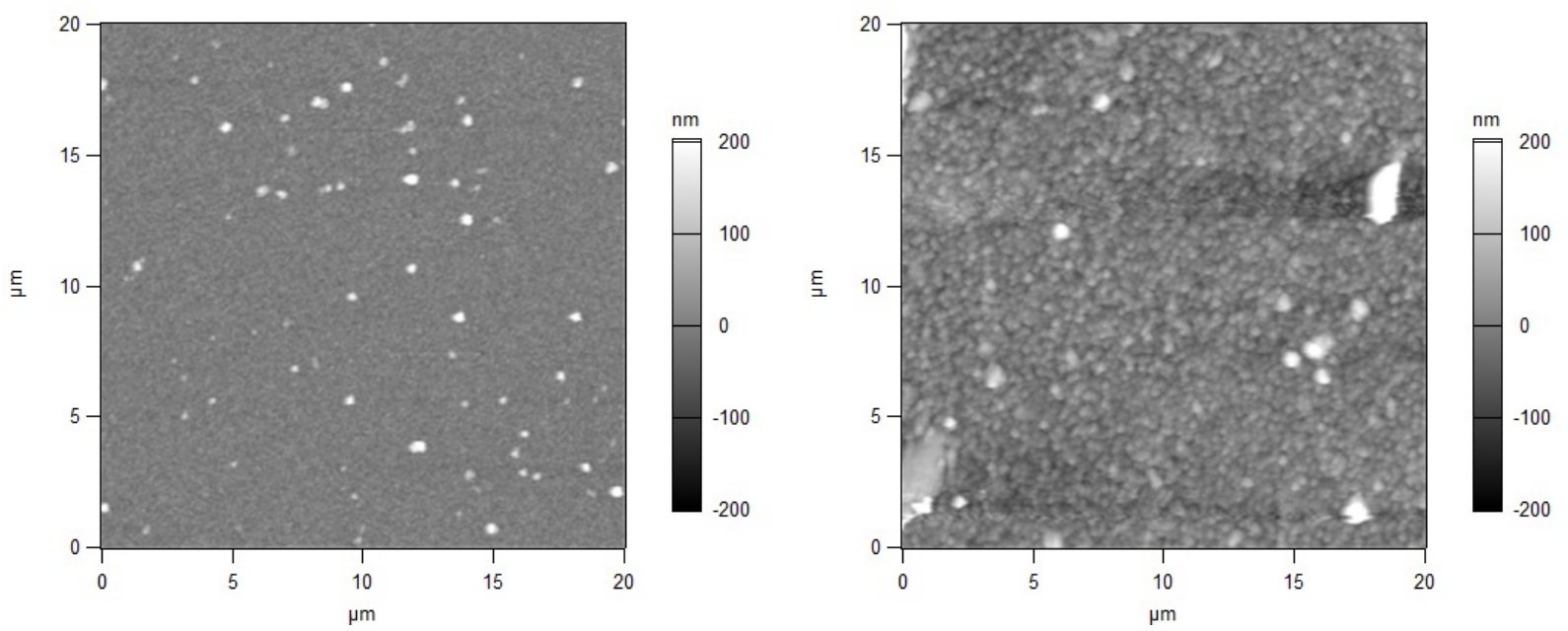

Figure S11. AFM micrographs of the surface of film formed from the condensation of COF-5 $($ HHTP +1$)$ from either flow (left) or static, sonicated conditions (right) conditions. The $\mathrm{R}_{\mathrm{a}}$ (arithmetic average roughness parameter) values are $10.4 \mathrm{~nm}$ and $26.0 \mathrm{~nm}$, respectively.
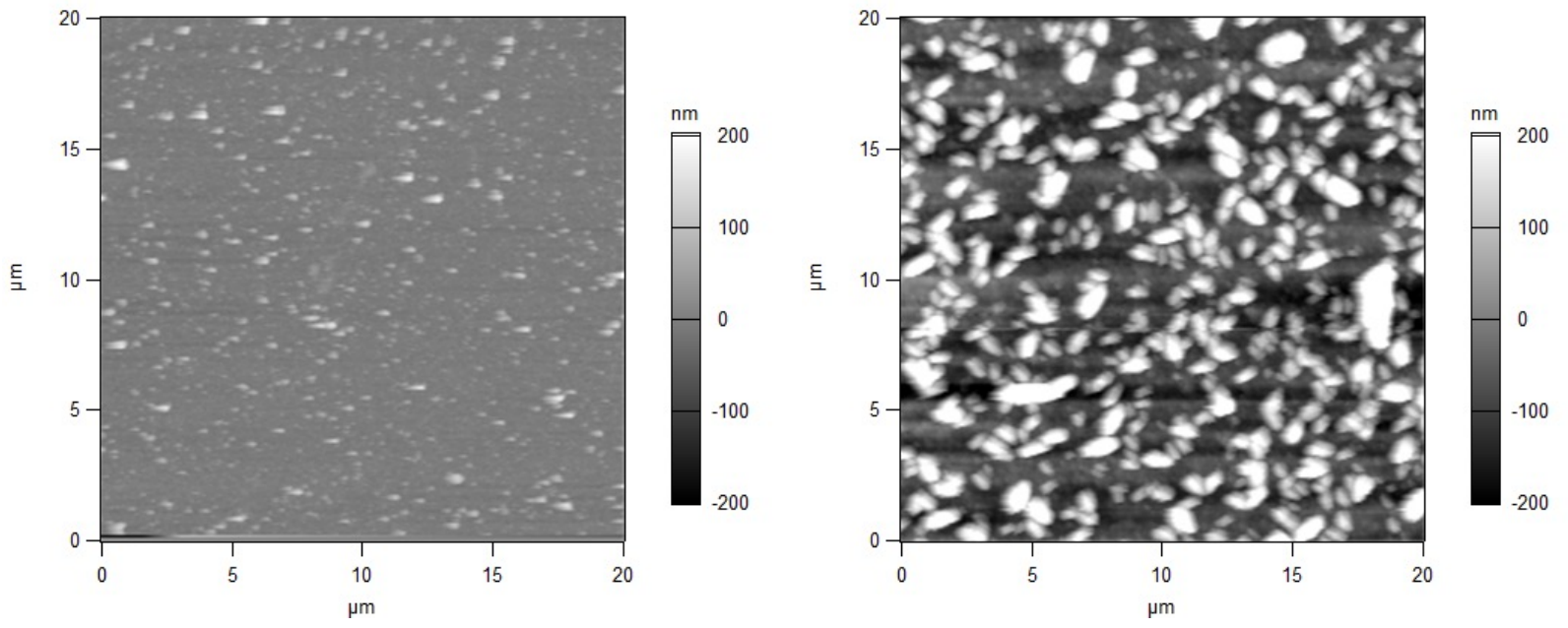

Figure S12. AFM micrographs of the surface of film formed from the condensation of DPBCOF (HHTP + 2) from either flow (left) or static, sonicated conditions (right) conditions. The $\mathrm{R}_{\mathrm{a}}$ (arithmetic average roughness parameter) values are $10.4 \mathrm{~nm}$ and $96.0 \mathrm{~nm}$, respectively. 

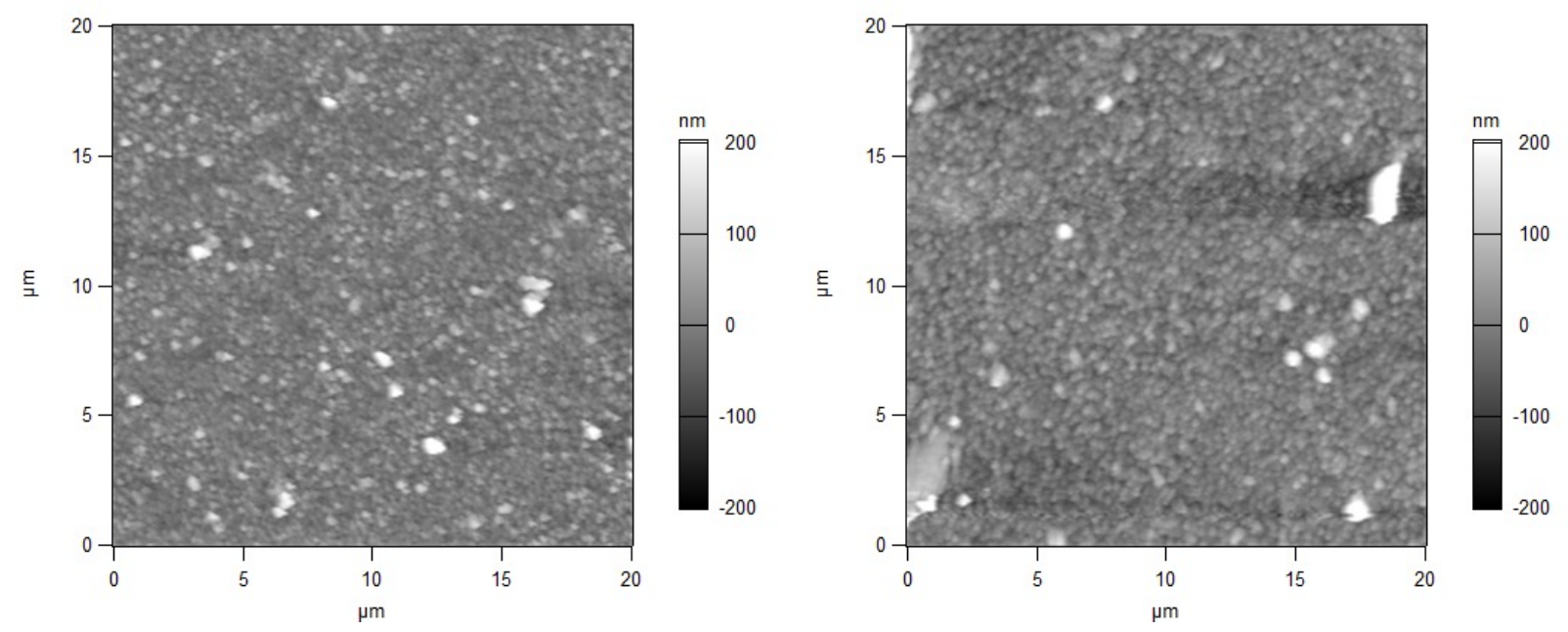

Figure S13. AFM micrographs of the surface of film formed from the condensation of TP-COF $($ HHTP +3$)$ from either flow (left) or static, sonictaed conditions (right) conditions. The $\mathrm{R}_{\mathrm{a}}$ (arithmetic average roughness parameter) values are $21.9 \mathrm{~nm}$ and $26.0 \mathrm{~nm}$, respectively.
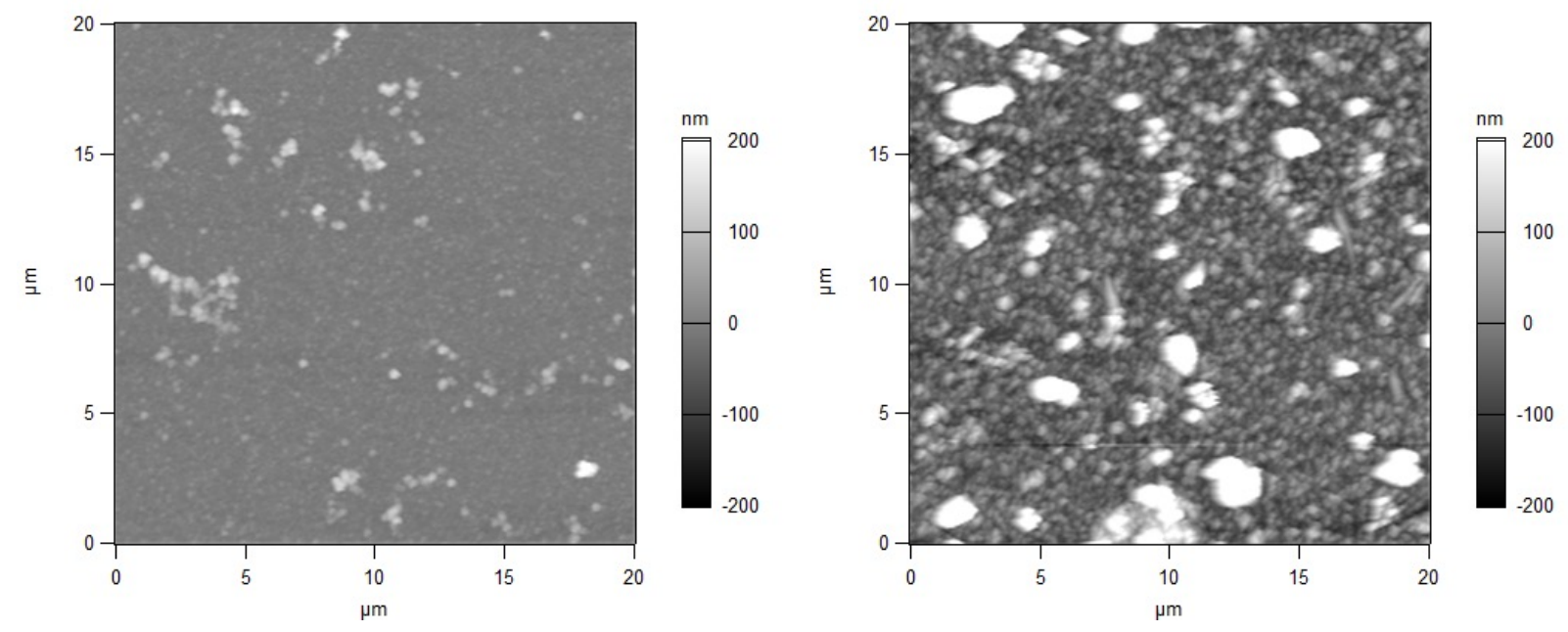

Figure S14. AFM micrographs of the surface of film formed from the condensation of COF-10 $(\mathrm{HHTP}+4)$ from either flow (left) or static, sonicated conditions (right) conditions. The $\mathrm{R}_{\mathrm{a}}$ (arithmetic average roughness parameter) values are $9.8 \mathrm{~nm}$ and $64.3 \mathrm{~nm}$, respectively. 


\section{G. Scanning Electron Microscopy}

\section{COF-5 Flow}

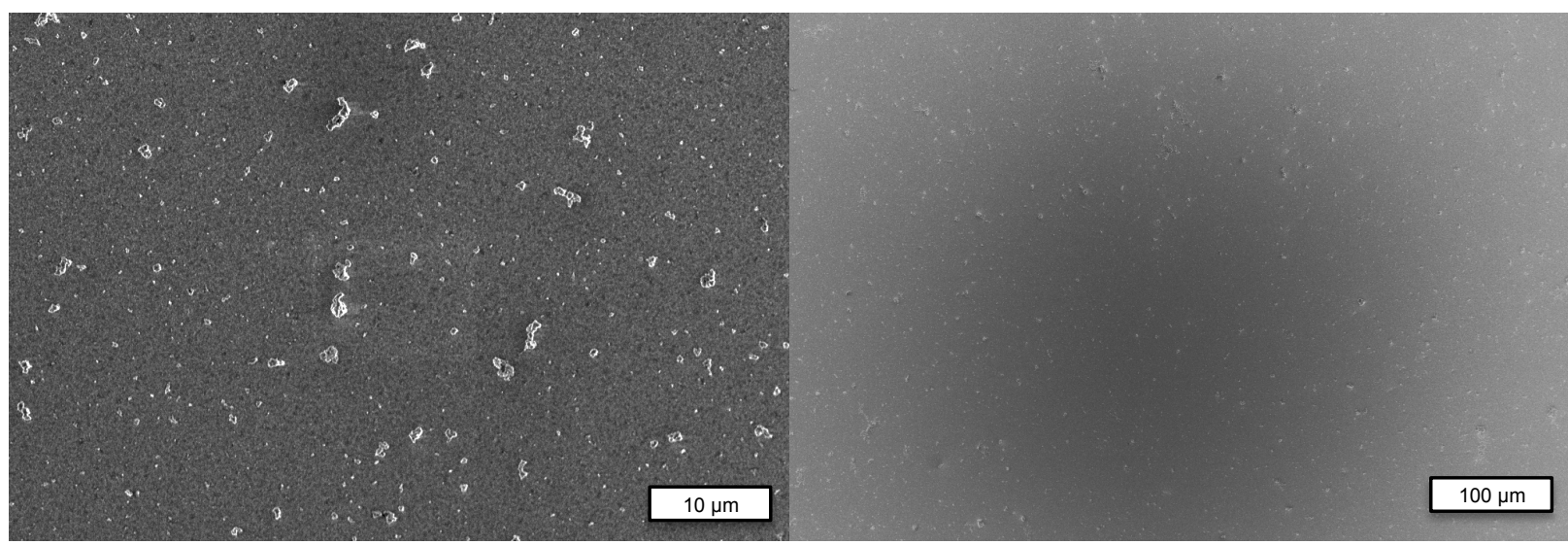

\section{COF-5 Static + Sonication}

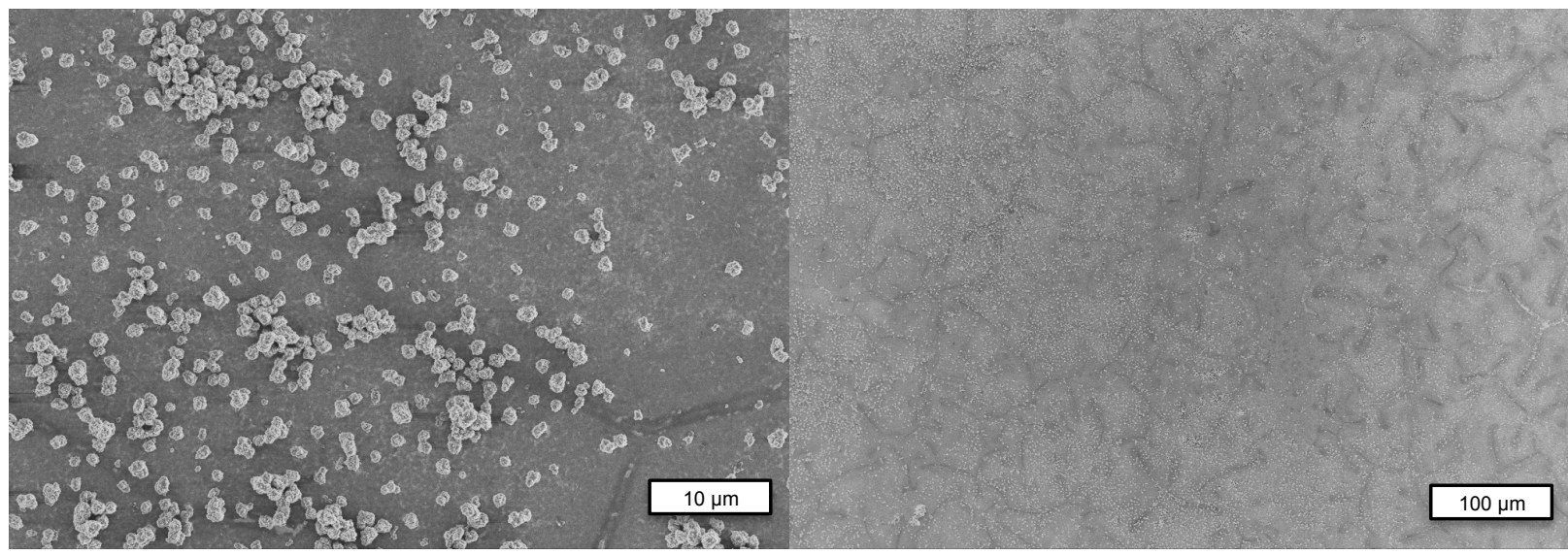

\section{COF-5 Static}

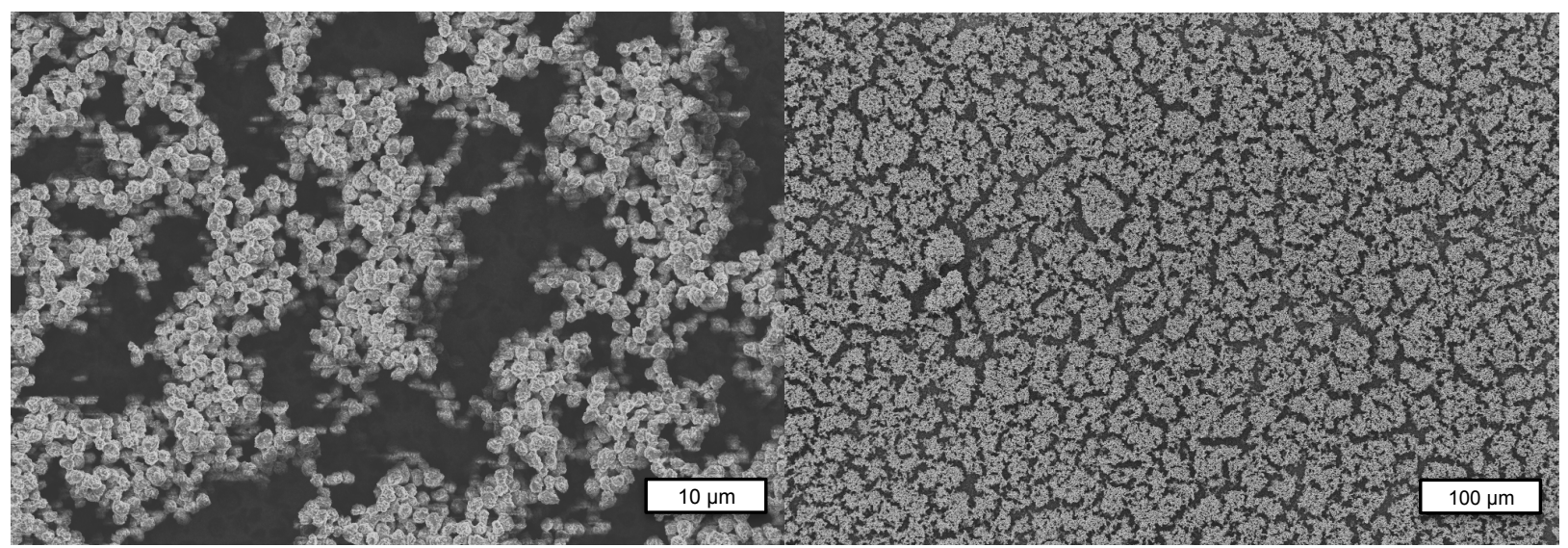

Figure S15. SEM micrographs of the surface of COF films formed from the condensation of COF-5 (HHTP + 1) grown from flow (first row), static conditions after sonication (second row) and before sonication (third row). 


\section{DPB-COF Flow}

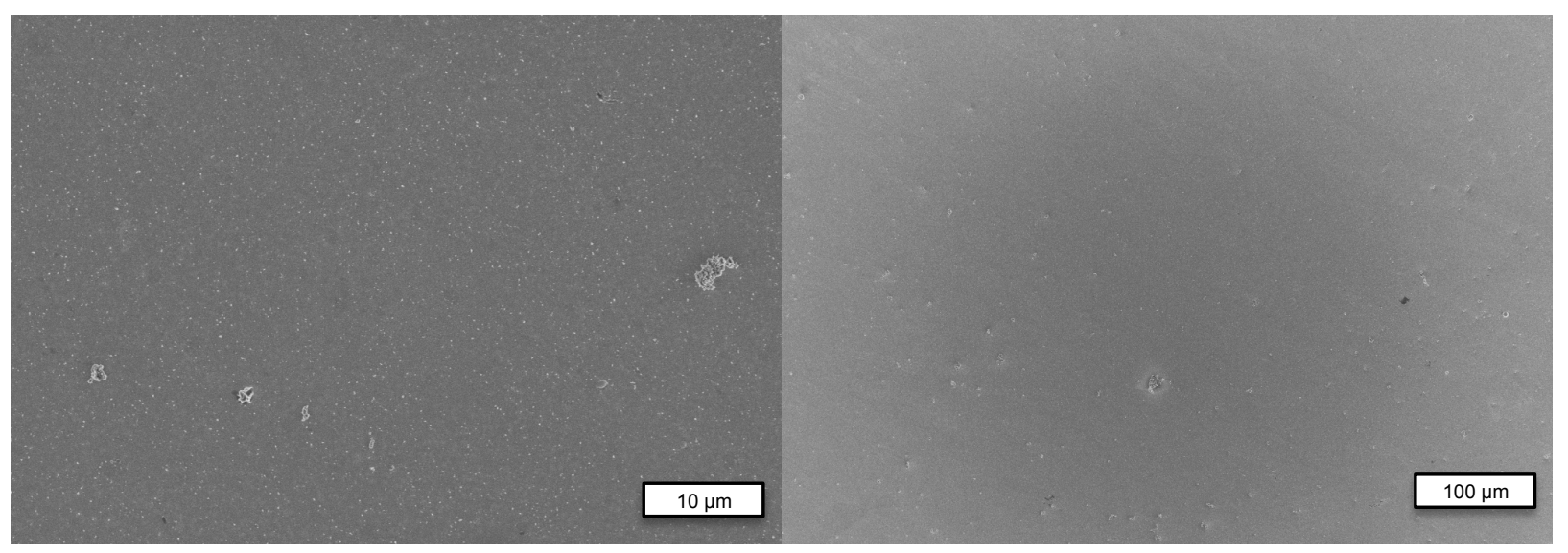

\section{DPB-COF Static + Sonication}

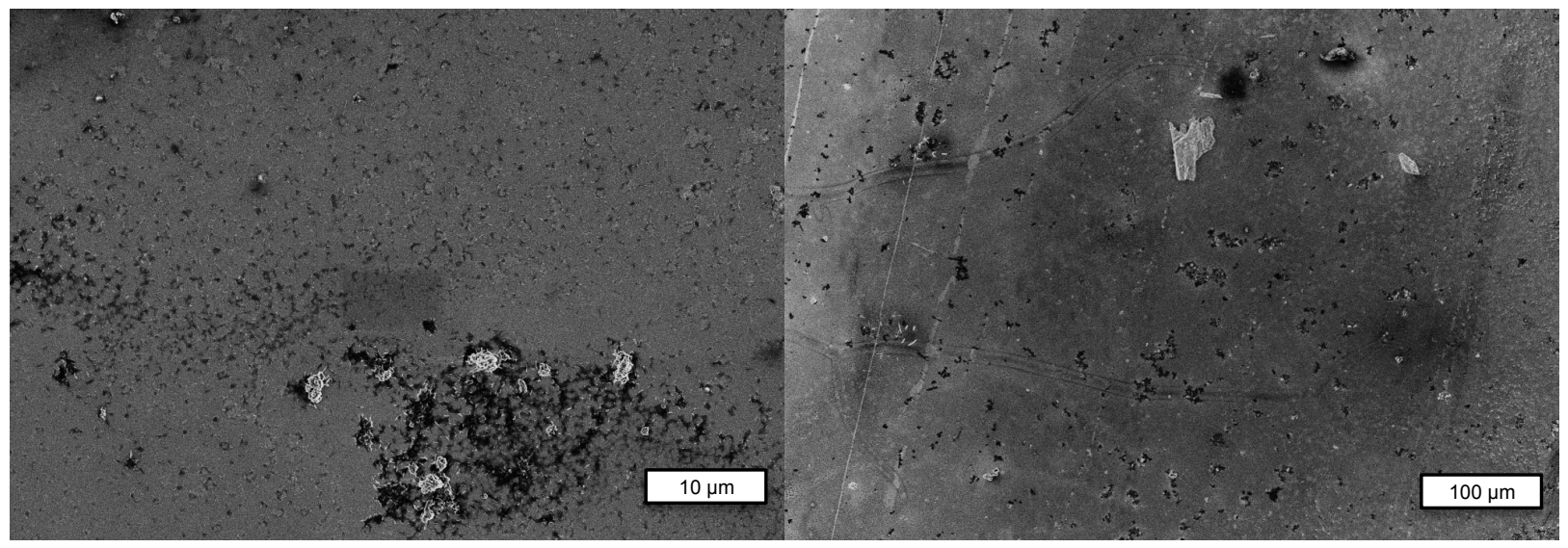

\section{DPB-COF Static}

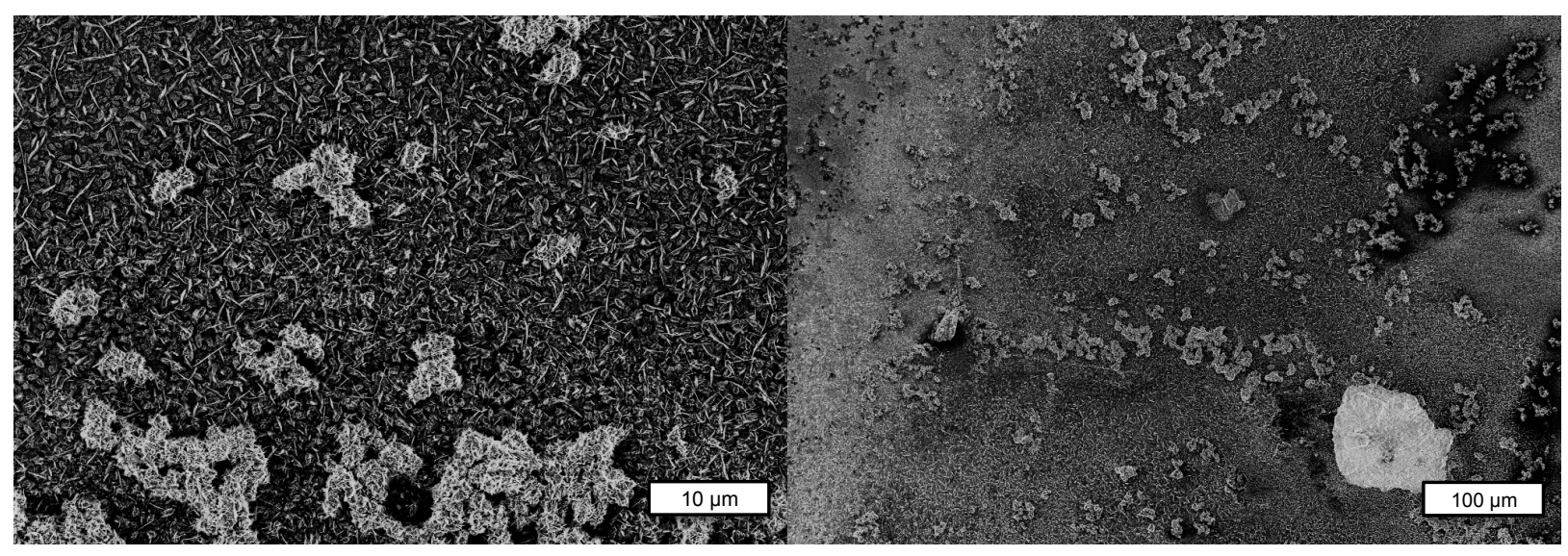

Figure S16. SEM micrographs of the surface of COF films formed from the condensation of DPB-COF (HHTP + 2) grown from flow (first row), static conditions after sonication (second row) and before sonication (third row). 


\section{TP-COF Flow}

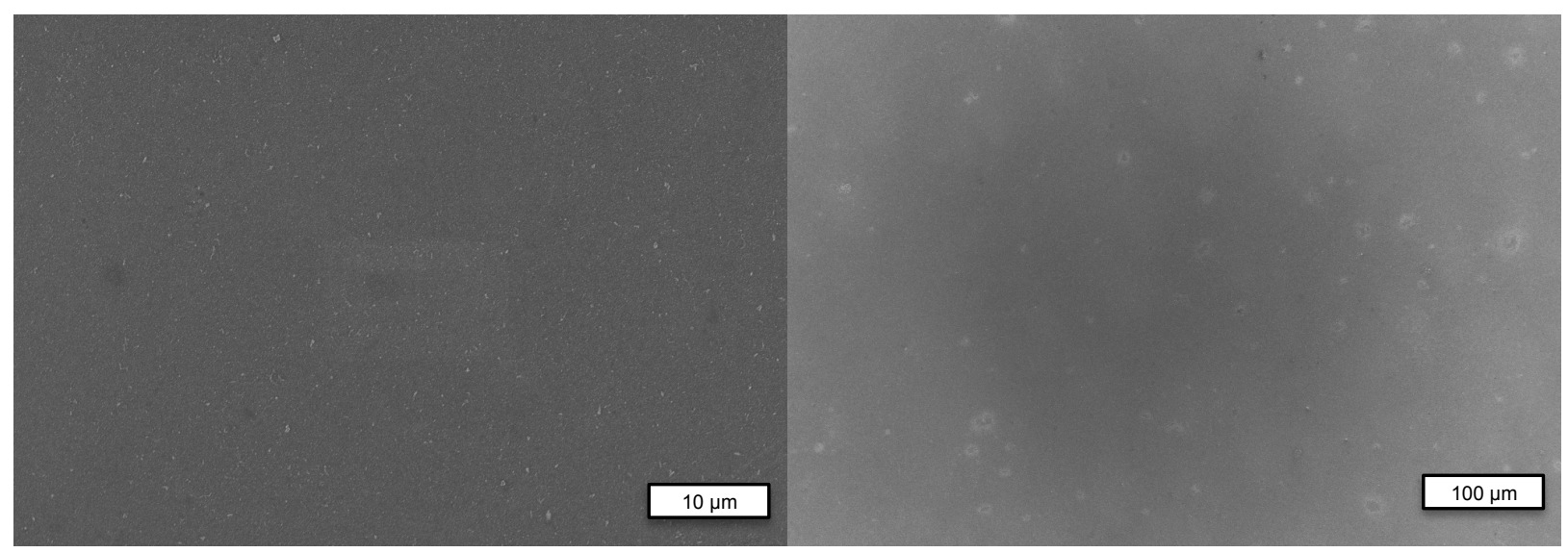

\section{TP-COF Static + Sonication}

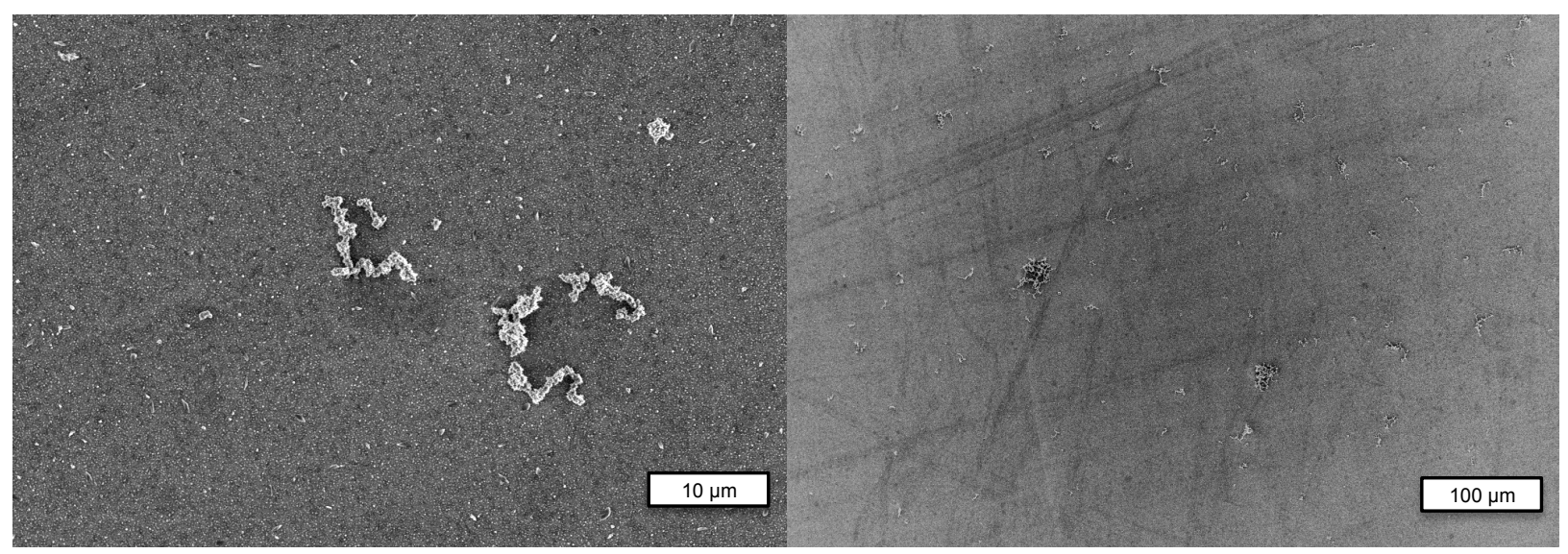

\section{TP-COF Static}

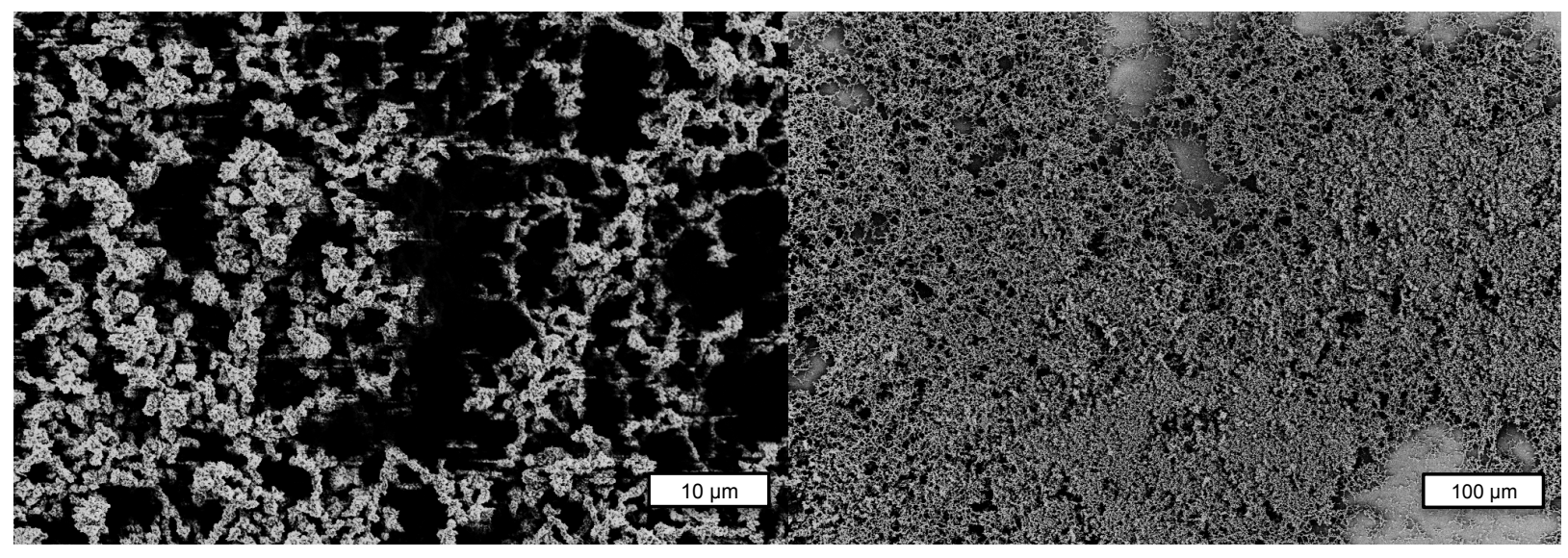

Figure S17. SEM micrographs of the surface of COF films formed from the condensation of TPCOF (HHTP +3 ) grown from flow (first row), static conditions after sonication (second row) and before sonication (third row). 


\section{COF-10 Flow}

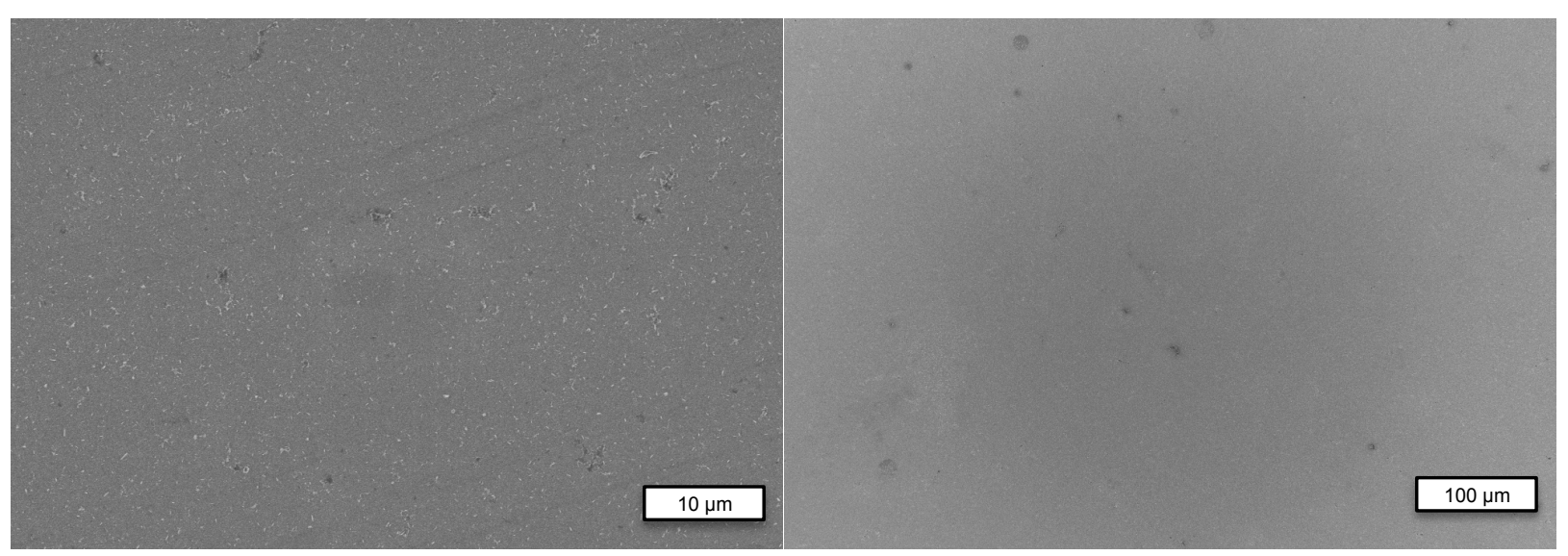

\section{COF-10 Static + Sonication}

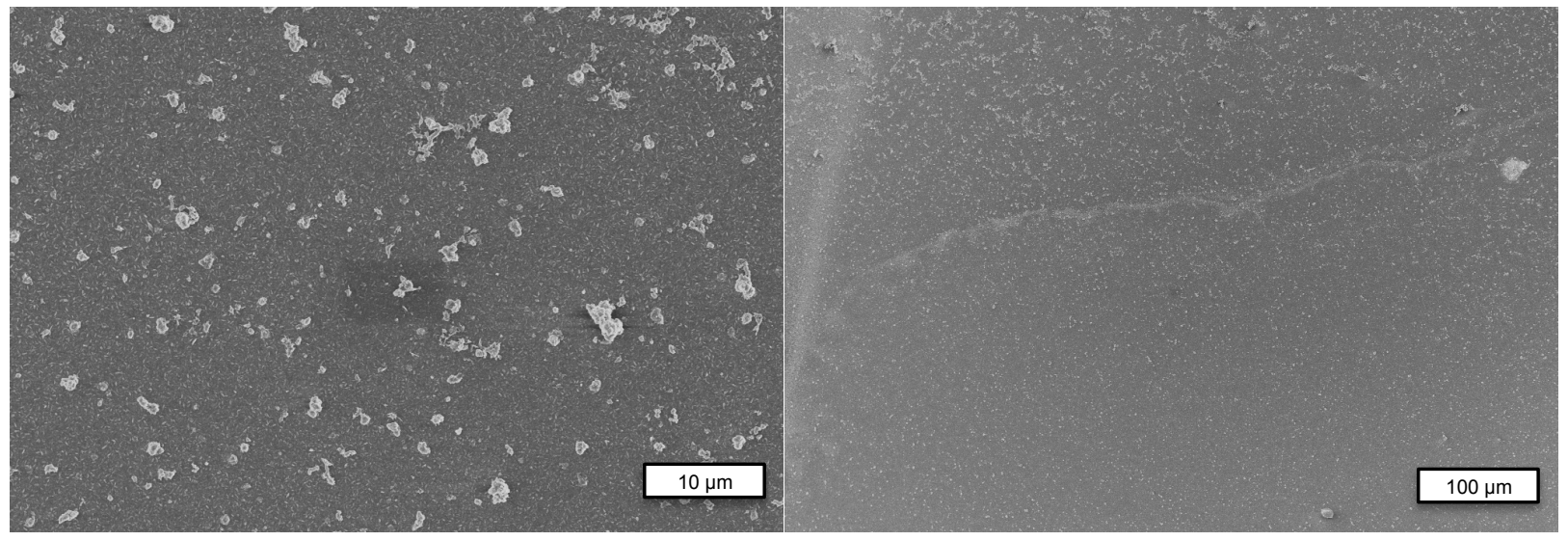

\section{COF-10 Static}

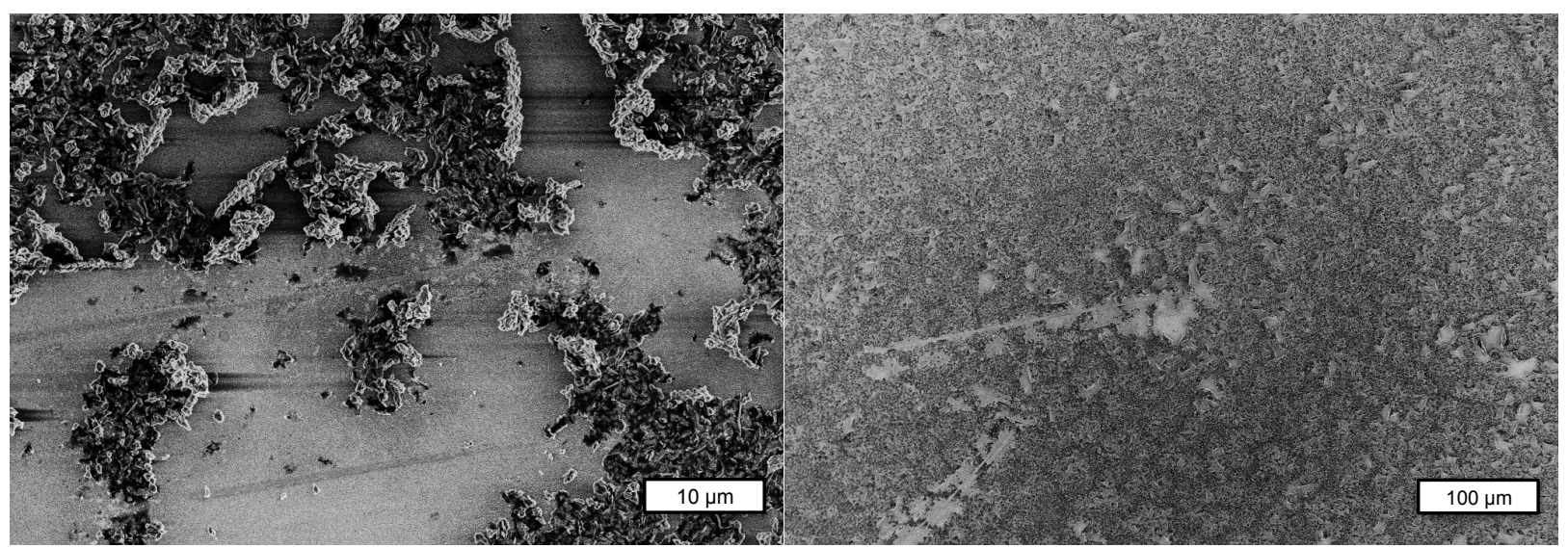

Figure S18. SEM micrographs of the surface of COF films formed from the condensation of COF-10 (HHTP + 4) grown from flow (first row), static conditions after sonication (second row) and before sonication (third row). 


\section{References}

(1) S. Wan, J. Guo, J. Kim, H. Ihee and D. Jiang, Angew. Chem. Int. Ed., 2008, 47, 8826-8830.

(2) E. L. Spitler, B. T. Koo, J. L. Novotney, J. W. Colson, F. J. Uribe-Romo, G. D. Gutierrez, P. Clancy and W. R. Dichtel, J. Am. Chem. Soc., 2011, 133, 19416- 19421.

(3) D. M. Smilgies, D. R. Blasini, S. Hotta, H. Yanagi, J. Synchrotron Radiat. 2005, 12, 807811. 